\title{
Clinical and in vitro Study of Novel Long Non-Coding RNA IncUSMycN in Breast Cancer
}

\author{
Reyhaneh Ravanbakhsh Gavgani ${ }^{1}$, Esmaeil Babaei ${ }^{{ }^{*}}$, Mohammad Ali \\ Hosseinpourfeizi ${ }^{1}$, Ashraf Fakhrjou ${ }^{2}$ and Vahid Montazeri ${ }^{3}$ \\ ${ }^{1}$ Department of Biological Sciences, School of Natural Sciences, University of Tabriz, Tabriz, Iran; \\ ${ }^{2}$ Department of Pathology, Faculty of Medicine, Tabriz University of Medical Sciences, \\ Tabriz, Iran; ${ }^{3}$ Department of Thoracic Surgery, Noor-Nejat Hospital, Tabriz, Iran
}

Received 3 October 2018; revised 9 December 2018; accepted 18 December 2018

\begin{abstract}
Background: Despite recent advances in diagnosis and treatment, breast cancer remains a leading cause of death in women worldwide. Long non-coding RNAs are a new class of RNA molecules that have been shown to participate in tumorigenesis. The aim of this study was to investigate the expression of IncUSMycN in tumor samples and to evaluate its potential role in the breast cancer cell line. Methods: Real-time polymerase chain reaction was employed to assess IncUSMycN expression in breast tumor tissues and cancer cell lines. Furthermore, small interfering RNA was used to knockdown IncUSMycN. Results: The data showed the significant up-regulation of IncUSMycN in tumor tissues compared to non-tumor specimens $(95 \% \mathrm{Cl}, p=0.002)$. Receiver operating characteristic (ROC) curve analysis demonstrated the biomarker potential of IncUSMycN (ROCAUC = $0.70, p<0.001)$ for invasive breast ductal carcinoma. Furthermore, IncUSMycN knockdown induced apoptosis and suppressed cellular migration in breast cancer cells $(p<0.01)$. Conclusion: The findings highlight the pivotal role of IncUSMycN in tumorigenesis, providing a new potential target for breast cancer therapy. DOI: 10.29252/ibj.23.5.303
\end{abstract}

Keywords: Breast cancer, Real-time polymerase chain reaction, siRNA

Corresponding Authors: Esmaeil Babaei

Department of Biological Sciences, School of Natural Sciences, University of Tabriz, Tabriz, Iran; Tel.: (+98-41) 33392686; Fax: (+98-41) 33356026; E-mail: babaei@tabrizu.ac.ir

\section{INTRODUCTION}

$\mathrm{B}$ reast cancer is the most common type of malignancy and the second leading cause of cancer-related death in women worldwide ${ }^{[1,2]}$. Improving diagnosis and treatment strategies in early stages of the disease remains a high priority; thus, a deeper understanding of the molecular and genetic networks that control tumor initiation and progression is crucial.

With the advent of new transcriptome sequencing technologies, it has been determined that almost $90 \%$ of the human genome is actively transcribed into noncoding RNAs ${ }^{[3]}$. Long non-coding RNAs (lncRNAs) are endogenous cellular RNA molecules longer than 200 nucleotides in length, which have lately received a great attention as important regulators of gene expression $^{[4]}$.

Increasing evidence has shown that IncRNAs can either directly or indirectly affect various cellular pathways, including those associated with cell survival, apoptosis, and metastasis; thus, aberrant expression of lncRNAs can adversely affect a wide range of biological processes resulting in different diseases, including cancer. IncRNAs such as MEG3, HOTAIR, and HULC have been demonstrated to be involved in tumorigenesis, tumor progression, and invasion ${ }^{[5,6]}$. These findings further emphasize the potential of lncRNAs as suitable diagnostic and/or prognostic biomarkers as well as novel targets in cancer therapy. In 2014, a lncRNA, denoted as long non-coding upstream MycN (lncUSMycN), was firstly reported in 
patients with neuroblastoma ${ }^{[7]}$. LncUSMycN gene is located on chromosome $2 \mathrm{p} 15.9,14-\mathrm{kbp}$ upstream of the MYCN transcription start site. A preliminary report has shown that the elevated expression of lncUSMycN is associated with a poor prognosis in neuroblastoma patients. In addition, lncUSMycN has a regulatory role in cell proliferation and tumorigenesis of neuroblastoma $^{[7]}$. However, little data on the expression and function of $\operatorname{lncUSMycN}$ in cancer exist; thus, we aimed to study the expression profile of lncUSMycN in invasive ductal carcinoma specimens in comparison with non-tumoral tissues. Moreover, siRNA-mediated knockdown was used to investigate the role of lncUSMycN in breast cancer cells.

\section{MATERIALS AND METHODS}

\section{Human tissue specimens}

Fifty-two specimens of surgically resected breast tumors with the invasive ductal carcinoma subtype and their adjacent non-tumor tissues (no obvious tumor cells were detectable; as evaluated by an expert pathologist) were collected from Noor-Nejat and Emam Reza Hospitals (Tabriz, Iran). The age of the patients ranged from 34 to 80 years (average: $51.29 \pm$ 1.73). A written consent was obtained from each patient prior to sample collection, and the study was carried out with the approval of the Ethical Committee of Tabriz University of Medical Sciences (approval number: IR.TBZMED.REC.1392.249). The specimens were immediately frozen in liquid nitrogen after surgery and stored at $-80{ }^{\circ} \mathrm{C}$. The TNM staging was carried out according to the American Joint Committee on Cancer (AJCC; $8^{\text {th }}$ edition).

\section{Cell culture}

All human breast cancer cell lines, including ZR-751 (ATCC NO. CRL-1500), MCF-7 (ATCC No. HTB22), and MDA-MB-231 (ATCC NO. HTB-26) were obtained from the National Cell Bank of Pasteur Institute of Iran, Tehran. ZR-75-1 and MCF-7 were grown in RPMI-1640 (Gibco, Life Technologies, Carlsbad, CA, USA), while MDA-MB-231 was cultured in DMEM (Sigma-Aldrich, St. Louis, MO, USA) supplemented with $10 \%$ heat-inactivated FBS (Gibco) and $100 \mathrm{U} / \mathrm{ml}$ of penicillin/streptomycin (10.000 U/mL, Gibco) in a humidified atmosphere of $5 \% \mathrm{CO}_{2}$ at $37{ }^{\circ} \mathrm{C}$.

RNA extraction, cDNA synthesis, and quantitative RT-PCR (qRT-PCR)

Total RNAs were extracted using TRIzol reagent (Invitrogen, Carlsbad, CA, USA) according to the manufacturer's instructions. cDNA was synthesized by reverse transcription of $1 \mu \mathrm{g}$ of total RNA using the PrimeScript RT kit (Takara, China) by following the manufacturer's protocol. qRT-PCR was carried out with primers specific for LncUSMycN, Bax, Bcl-2, Ecadherin, MMP-9, and $\beta$-actin using SYBR® Premix EX TaqTM II (Tli RNaseH Plus; Takara) by Corbett Rotor-Gene 6000 (Corbett Life Sciences, Germany). Primer sequences and qRT-PCR conditions are outlined in Table 1. All gene expression levels were normalized to $\beta$-actin as reference.

\section{PCR product sequencing}

To further confirm the expression of lncUSMycN, RT-PCR products were subjected to Sanger sequencing, subsequently interpreted by Chromas Pro 2.4.1 and aligned in BLAST. Primers used for sequencing were as forward: 5'-GTGTGTCTGTTGCT GAATG-3' and reverse: 5'-CTGTGTGTGCTTTGG TGCT-3'.

\section{siRNA transfection}

To investigate the role of lncUSMycN, its expression was suppressed via siRNA-mediated gene silencing. Therefore, pre-designed negative control siRNA (siNC) and custom-synthesized si-lncUSMycN against lncUSMycN (target sequence: 5'-GGCAGGGAAGGT GTTGTTGTT-3') were purchased from Dharmacon (Lafayette, CO, USA). Both siRNAs were labeled with 6-Carboxyfluorescein (6-FAM) at their 3' end to measure them during in vitro experiments. Cells were transfected using HiPerFect Transfection Reagent (Qiagen, Germany) according to the manufacturer's protocol. Assays were performed $72 \mathrm{~h}$ after transfection.

\section{Study of apoptosis}

To study apoptosis and necrosis, acridine orange/ethidium bromide staining was employed. Briefly, ZR-75-1 cells $\left(2.5 \times 10^{5}\right)$ were seeded onto 24 well plates and cultured for $24 \mathrm{~h}$. Then the cells were transfected with si-lncUSMycN and si-NC separately according to the manufacturer's instruction. After $72 \mathrm{~h}$, the cells were detached by Trypsin-EDTA $(0.25 \%$; HyClone; GE Healthcare Life Sciences, USA) and transferred to glass slides, followed by staining with acridine orange/ethidium bromideAO/EtBr solution containing $100 \mu \mathrm{g} / \mathrm{ml}$ acridine orange and $100 \mu \mathrm{g} / \mathrm{ml}$ ethidium bromide (Sigma-Aldrich). Finally, the cells were analyzed under fluorescence microscope (Olympus BX 41, Germany). In addition, the expression of apoptosis-related genes $\mathrm{Bax}$ and $\mathrm{Bcl}-2$ was evaluated by qRT-PCR. 
Table 1. The sequences of the primers used in this study and their qPCR programs

\begin{tabular}{|c|c|c|c|}
\hline Primer name & Primer sequence $\left(5^{\prime}-3^{\prime}\right)$ & $\begin{array}{c}\text { qPCR cycling } \\
\text { program* min }(s)\end{array}$ & $\begin{array}{l}\text { Product } \\
\text { size (bp) }\end{array}$ \\
\hline $\begin{array}{l}\text { LncUSMycN-F } \\
\text { LncUSMycN-R }\end{array}$ & $\begin{array}{l}\text { ACTTGTCCTGCGTGCTTGTT } \\
\text { TGTGTGTGCTTTGGTGCTCA }\end{array}$ & $\begin{array}{l}\text { D: } 95(30) \\
\text { A: } 57(22) \\
\text { E: } 72(20)\end{array}$ & 218 \\
\hline $\begin{array}{l}\text { Bax-F } \\
\text { Bax-R }\end{array}$ & $\begin{array}{l}\text { GCAAACTGGTGCTCAAGG } \\
\text { ACTCCCGCCACAAAGA }\end{array}$ & $\begin{array}{l}\text { D: } 95(30) \\
\text { A: } 63(35) \\
\text { E: } 72(30)\end{array}$ & 236 \\
\hline $\begin{array}{l}\text { BCL2-F } \\
\text { BCL2-R }\end{array}$ & $\begin{array}{l}\text { TGGGAAGTTTCAAATCAGC } \\
\text { GCATTCTTGGACGAGGG }\end{array}$ & $\begin{array}{l}\text { D: } 95(25) \\
\text { A: } 63(30) \\
\text { E: } 72(30)\end{array}$ & 298 \\
\hline $\begin{array}{l}\text { E-cadherin-F } \\
\text { E-cadherin- } R\end{array}$ & $\begin{array}{l}\text { AGTACAACGACCCAACCCAAG } \\
\text { GCAAGAATTCCTCCAAGAATCC }\end{array}$ & $\begin{array}{l}\text { D: } 95(30) \\
\text { A: } 57(22) \\
\text { E: } 72(20)\end{array}$ & 235 \\
\hline $\begin{array}{l}\text { MMP-9-F } \\
\text { MMP-9-R }\end{array}$ & $\begin{array}{l}\text { CCGCTCACCTTCACTCGC } \\
\text { ACCACAACTCGTCATCGTC }\end{array}$ & $\begin{array}{l}\text { D: } 95(30) \\
\text { A: } 63(35) \\
\text { E: } 72(30)\end{array}$ & 174 \\
\hline $\begin{array}{l}\beta \text {-actin-F } \\
\beta \text {-actin-R }\end{array}$ & $\begin{array}{l}\text { AGAGCTACGAGCTGCCTGAC } \\
\text { AGCACTGTGTTGGCGTACAG }\end{array}$ & & 184 \\
\hline
\end{tabular}

\section{Cell cycle analysis}

To perform cell cycle analysis, ZR-75-1 cells (2.5 $\mathrm{X} 10^{5}$ ) were seeded in 24-well plates for $24 \mathrm{~h}$, followed by transfection with si-lncUSMycN and si-NC separately according to manufacturer's instructions. After $72 \mathrm{~h}$, the cells were detached by Trypsin-EDTA solution at $37^{\circ} \mathrm{C}$ for $5 \mathrm{~min}$, followed by adding $10 \%$ FBS-RPMI 1640 medium, in order to inhibit Trypsin activity. Afterward, the cells were washed by cold PBS, followed by fixation using ice-cold ethanol (70\% $\mathrm{w} / \mathrm{w})$. Next, the cells were incubated in a freshly prepared solution containing $0.1 \%$ Triton X-100, RNase A $(50 \mu \mathrm{g} / \mathrm{ml}$; Sigma-Aldrich), and propidium iodide (PI) $\left(50 \mu \mathrm{g} / \mathrm{ml}\right.$; Sigma-Aldrich) at $4{ }^{\circ} \mathrm{C}$ for 15 min. Then the stained cells were analyzed by flow cytometry (BD FACS Calibur flow cytometer, BD Biosciences, USA). The percentage of cells in the subG1 and G1 phases were analyzed by FlowJO 7.6.1 software.

\section{Wound healing assay}

In order to get around $90 \%$ confluency after $24 \mathrm{~h}$ of culturing, ZR-75-1 cells were seeded at appropriate numbers into a 24-well plate in complete medium. After $24 \mathrm{~h}$, a single wound was created in the middle of the well using a sterile $200 \mu \mathrm{l}$ pipette tip. After removing detached cells with PBS (phosphate buffered saline), the adherent cellular layers were separately transfected with si-lncUSMycN and si-NC according to the manufacturer's instructions. After $72 \mathrm{~h}$, the cells migrated into the wounded area were photographed under an inverted microscope (Olympus, Japan). Beside wound healing assay, the expression of genes implicated in invasion and metastasis, including $\mathrm{CDH}$ (E-cadherin) and MMP-9, was assessed at mRNA levels.

\section{Statistical analysis}

Relative Expression Software Tool (REST) 2009 was used to evaluate the statistical differences in lncUSMycN expression of the breast cancer tissues relative to their non-tumoral counterparts. The fold change and relative expression of $\operatorname{lncUSMycN}$ were calculated by the $2^{-\Delta \Delta \mathrm{Ct}}(\Delta \Delta \mathrm{Ct}=\Delta \mathrm{Ct}$ [treated cells] $\Delta \mathrm{Ct}$ [control] $)$ and $2^{-\Delta \mathrm{Ct}}(\Delta \mathrm{Ct}=\mathrm{Ct}[\mathrm{lncUSMycN}]-\mathrm{Ct}$ [ $\beta$-actin]) methods, respectively. Also, Student's $t$-test and one-way ANOVA were performed to compare two or more groups, respectively. $p$ values $<0.05$ were considered to be statistically significant. Receiver operating characteristic (ROC) curve analysis was plotted to assess the biomarker potential of lncUSMycN in breast cancer. All experiments were repeated at least three times, and data were represented as mean \pm SEM (standard error of mean).

\section{RESULTS}

\section{LncUSMycN is up-regulated in breast cancer tissues}

To study the role of $\operatorname{lncUSMycN}$ in breast cancer, lncUSMycN expression was first detected in breast 
(A)

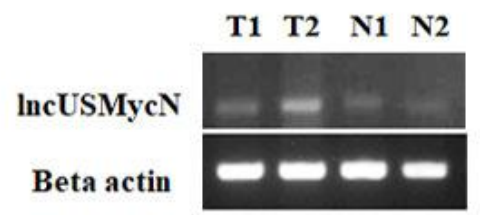

(C)

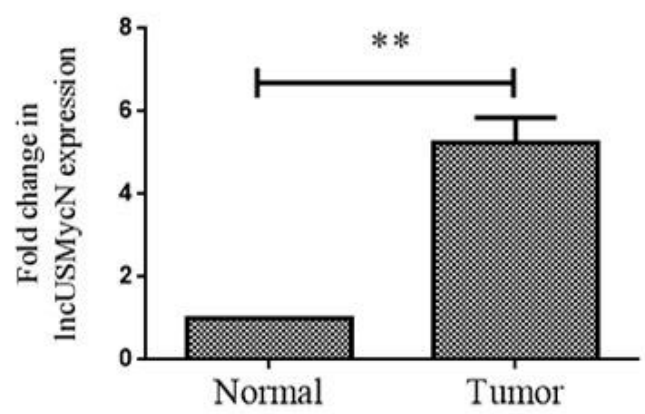

(B)
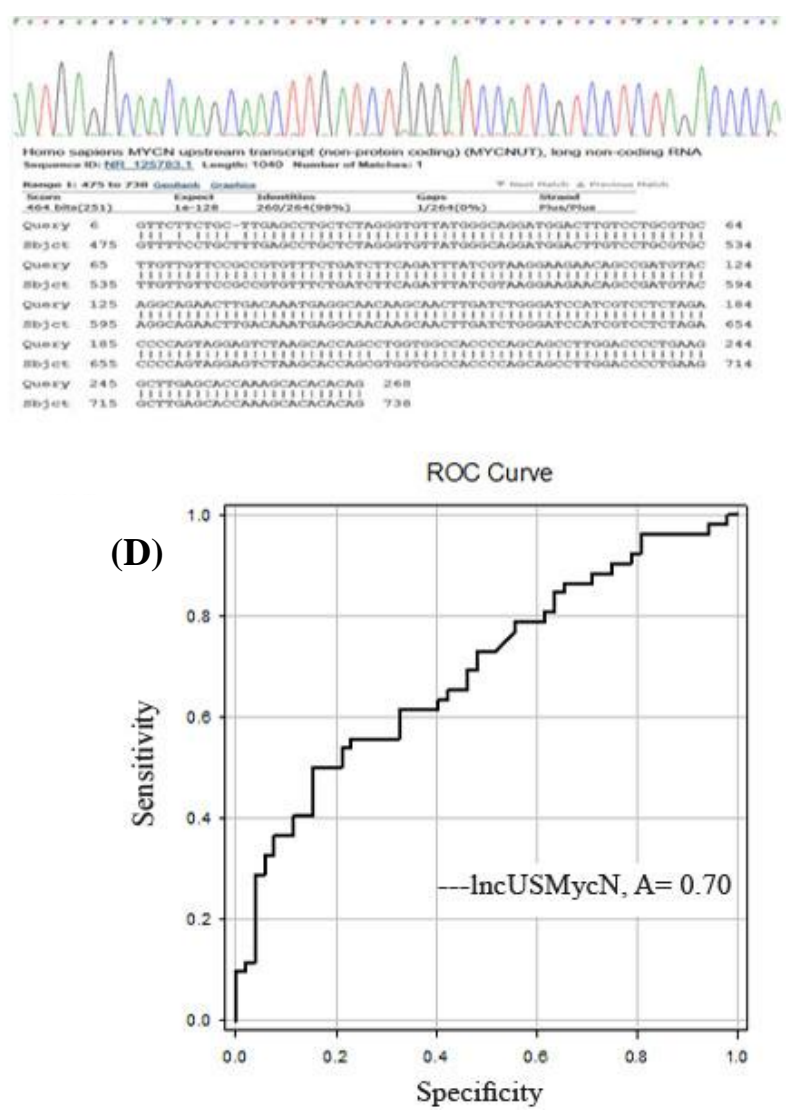

Fig. 1. Expression of lncUSMycN in breast cancer and receive operating characteristic (ROC) curve analysis for prediction of breast cancer prognosis. (A) Amplified lncUSMycN and $\beta$-actin on $2 \%$ agarose gel; (B) confirmation of lncUSMycN expression by Sanger sequencing; (C) qRT-PCR analysis of lncUSMycN expression level in cancerous and adjacent non-cancerous breast tissues. lncUSMycN was up-regulated in tumor tissues compared to adjacent normal tissues; (D) ROC curve for lncUSMycN to discriminate between tumor and normal tissues. The area under the ROC curve (AUC) was $0.70(p<0.001)$. The sensitivity and specificity were 0.85 and 0.55 , respectively, and cut-off value was $17.5\left(^{* *} p<0.01\right)$.

tumor tissues. As Figure 1A shows, the PCR amplicon for lncUSMycN is specifically synthesized by primers. The PCR product was validated by Sanger sequencing (Fig. 1B). The results for expression studies showed that $\operatorname{lncUSMycN}$ is significantly up-regulated by 5.2 fold in cancerous tissues compared to non-cancerous specimens $(95 \% \mathrm{CI}, 5.241 \pm 0.355, p=0.002$, Fig. 1C). Furthermore, it was found that IncUSMycN expression was significantly correlated with early stages of breast cancer $(p=0.004)$. No association was detected between expression of IncUSMycN and other clinicopathological features, including age, lymph node metastasis, differentiation, tumour location and progesterone, estrogen, and HER-2 receptor levels (Table 2). ROC curve analysis was done to determine whether or not cancerous and non-cancerous tissue could be distinguished by the expression level of lncUSMycN. The area under the ROC curve (AUC) was $0.70(p<0.001)$. The sensitivity and specificity were 0.85 and 0.55 , respectively, and the cut-off value was 17.5 (Fig. 1D).

\section{IncUSMycN expressed in breast cancer cell lines}

To further evaluate the potential role of $\operatorname{lncUSMycN}$ in breast cancer, siRNA-based knockdown was employed in ZR-75-1, MCF-7, and MDA-MB-231 cell lines. However, due to the inherent higher expression of lncUSMycN in ZR-75-1, the data for this cell line are illustrated in Figure 2A. qRT-PCR data revealed that $\operatorname{lncUSMycN}$ was significantly knocked down in siRNA-treated cells by more than $90 \%$ efficiency. Fold reduction in $\operatorname{lncUSMycN}$ expression following siIncUSMycN transfection was significant $(p<0.001$, Fig. 2B).

\section{IncUSMycN knockdown induced apoptosis}

To study apoptosis by focusing on morphological changes, siRNA-treated and control cells were stained with acridine orange/ethidium bromide. As shown in Figure 3A, the knockdown of lncUSMycN induces apoptosis-related morphological changes. Consistent with the morphological changes, the gene expression data revealed that IncUSMycN 
Table 2. The relationship between lncUSMycN expression levels and clinicopathological features of patients with breast cancer

\begin{tabular}{|c|c|c|c|}
\hline Characteristics & $\begin{array}{c}\text { No. of } \\
\text { patients }(\%)\end{array}$ & $\begin{array}{c}\text { IncUSMycN } \\
\Delta \mathrm{Ct} \text { mean } \pm \text { SEM }\end{array}$ & $\begin{array}{c}p \\
\text { value }\end{array}$ \\
\hline \multicolumn{4}{|l|}{ Age } \\
\hline$<45$ & $24(46.7)$ & $18.11 \pm 0.86$ & \multirow{2}{*}{0.379} \\
\hline$>45$ & $28(53.3)$ & $17.13 \pm 0.70$ & \\
\hline \multicolumn{4}{|l|}{ Tumor Size } \\
\hline$<2 \mathrm{~cm}$ & $24(46.2)$ & $16.34 \pm 0.72$ & \multirow{2}{*}{0.148} \\
\hline$>2 \mathrm{~cm}$ & $20(38.5)$ & $18.04 \pm 0.92$ & \\
\hline \multicolumn{4}{|c|}{ TNM* clinical stage } \\
\hline I & $17(32.7)$ & $15.80 \pm 0.92$ & \multirow{3}{*}{$0.004 * *$} \\
\hline II & $14(26.9)$ & $16.43 \pm 1.06$ & \\
\hline III & $14(26.9)$ & $20.28 \pm 0.88$ & \\
\hline \multicolumn{4}{|c|}{ Lymphatic methastasis } \\
\hline Absent & $17(32.7)$ & $15.79 \pm 0.92$ & \multirow{2}{*}{0.052} \\
\hline Present & $28(53.8)$ & $18.11 \pm 0.72$ & \\
\hline \multicolumn{4}{|l|}{ Differentiation } \\
\hline Poor & $5(9.6)$ & $14.16 \pm 1.53$ & \multirow{3}{*}{0.176} \\
\hline Moderate & $35(67.3)$ & $17.58 \pm 0.63$ & \\
\hline Well & $5(9.6)$ & $17.91 \pm 2.31$ & \\
\hline \multicolumn{4}{|c|}{ Progestron expression (\%) } \\
\hline$<30$ & $18(34.6)$ & $17.54 \pm 0.95$ & \multirow{2}{*}{0.38} \\
\hline$>30$ & $16(30.8)$ & $16.31 \pm 1.02$ & \\
\hline \multicolumn{4}{|c|}{ Estrogen expression (\%) } \\
\hline$<30$ & $17(32.7)$ & $18.16 \pm 0.81$ & \multirow{2}{*}{0.085} \\
\hline$>30$ & $17(32.7)$ & $15.77 \pm 1.07$ & \\
\hline \multicolumn{4}{|l|}{ HER-2 status } \\
\hline Negative & $16(30.8) 15$ & $16.86 \pm 1.04$ & \multirow{2}{*}{0.858} \\
\hline Positive & $(28.8)$ & $17.14 \pm 1.10$ & \\
\hline \multicolumn{4}{|l|}{ Location } \\
\hline Right & $20(38.5)$ & $16.68 \pm 0.88$ & \multirow{2}{*}{0.214} \\
\hline Left & $23(44.2)$ & $18.12 \pm 0.73$ & \\
\hline
\end{tabular}

The value in bold is significant $\left({ }^{* *} p<0.01\right)$

knockdown significantly up-regulated Bax expression $(p=0.015)$ and down-regulated $\mathrm{Bcl}-2$ at the mRNA level in ZR-75-1 cells ( $p=0.041$, Fig. 3B).

\section{LncUSMycN knockdown affected ZR-75-1 cell cycle distribution}

Flow cytometry was applied to study the growth inhibitory effect of lncUSMycN knockdown on ZR-751 cells. Our data showed that IncUSMycN knockdown influenced ZR-75-1 cell population in subG1 and G1 phases. The results for subG1 and G1 were $0.94 \%$ and $77.2 \%$, respectively. Nevertheless, siRNA-transfected cell population for subG1 and G1 was reported as $8.84 \%$ and $65.6 \%$, respectively. Therefore, cell cycle analysis showed a significant reduction in G1 phase ( $p<0.05$ ), while the subG1 population, representing apoptotic cells, was significantly increased $72 \mathrm{~h}$ after si-lncUSMycN transfection ( $p<0.05$, Fig. 4).

\section{IncUSMycN knockdown affects epithelial- mesenchymal transition (EMT)}

To explore the role of lncUSMycN in invasion and EMT, the invasive behavior of ZR-75-1 cells following depletion of lncUSMycN was examined. The effect of lncUSMycN on migration was determined by wound healing assay. The results revealed that the knockdown of lncUSMycN significantly decreased the cell migration capacity as compared to non-transfected 


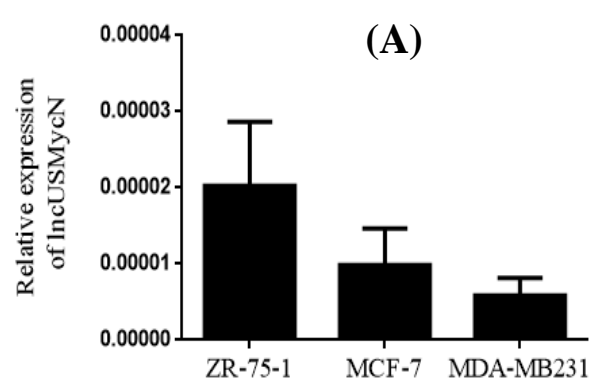

Breast cancer cell lines

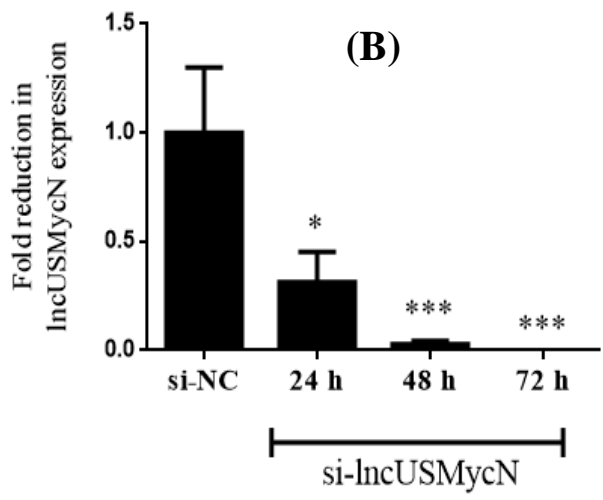

Fig. 2. IncUSMycN expression in breast cancer cell lines and siRNA-mediated knockdown. (A) LncUSMycN expression levels in breast cancer cell lines, including ZR-75-1, MCF-7, and MDA-MB-231; (B) the efficiency of siRNA-mediated knockdown evaluated $24 \mathrm{~h}, 48 \mathrm{~h}$, and $72 \mathrm{~h}$ after transfection by RT-qPCR in ZR-75-1 cells. ${ }^{*} p<0.05,{ }^{* * *} p<0.001$. si-NC, siRNA negative control; silncUSMycN, siRNA lncUSMycN

(A)
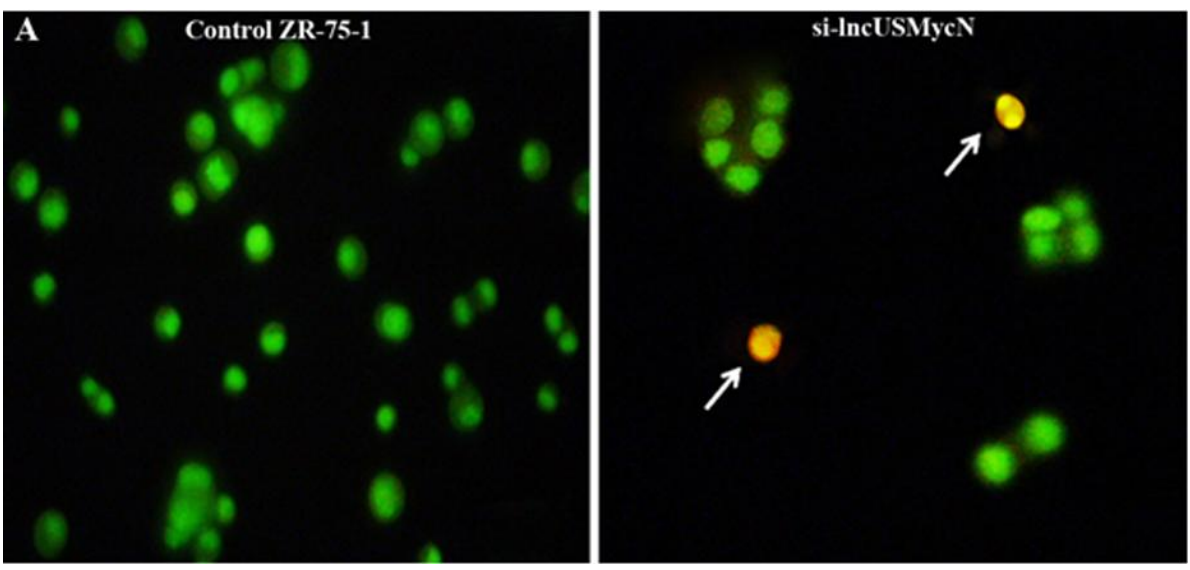

(B)

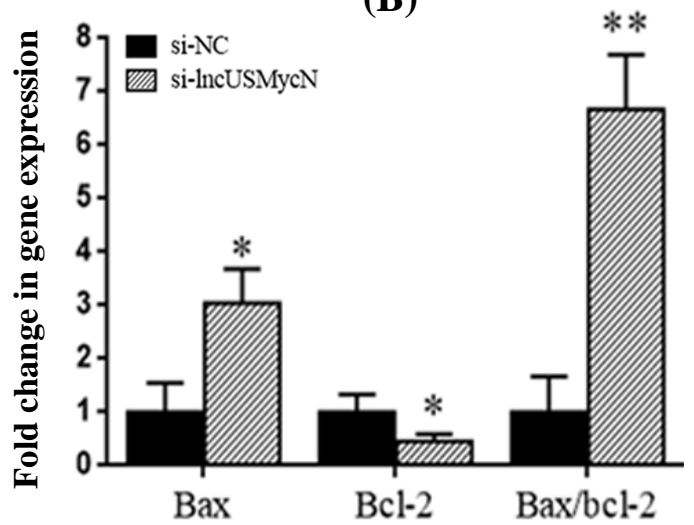

Fig. 3. Effects of lncUSMycN knockdown on apoptosis. (A) Morphological evaluation of the apoptotic cells stained with acridine orange/ethidium bromide (AO/EtBr). Arrows indicate apoptotic cells. (magnification 200×); (B) expression of Bax and Bcl-2 in ZR$75-1$ cells by qRT-PCR 72 after lncUSMycN knockdown. ${ }^{*} p<0.05,{ }^{* *} p<0.01$. si-NC, siRNA negative control; si-lncUSMycN, siRNA lncUSMycN 

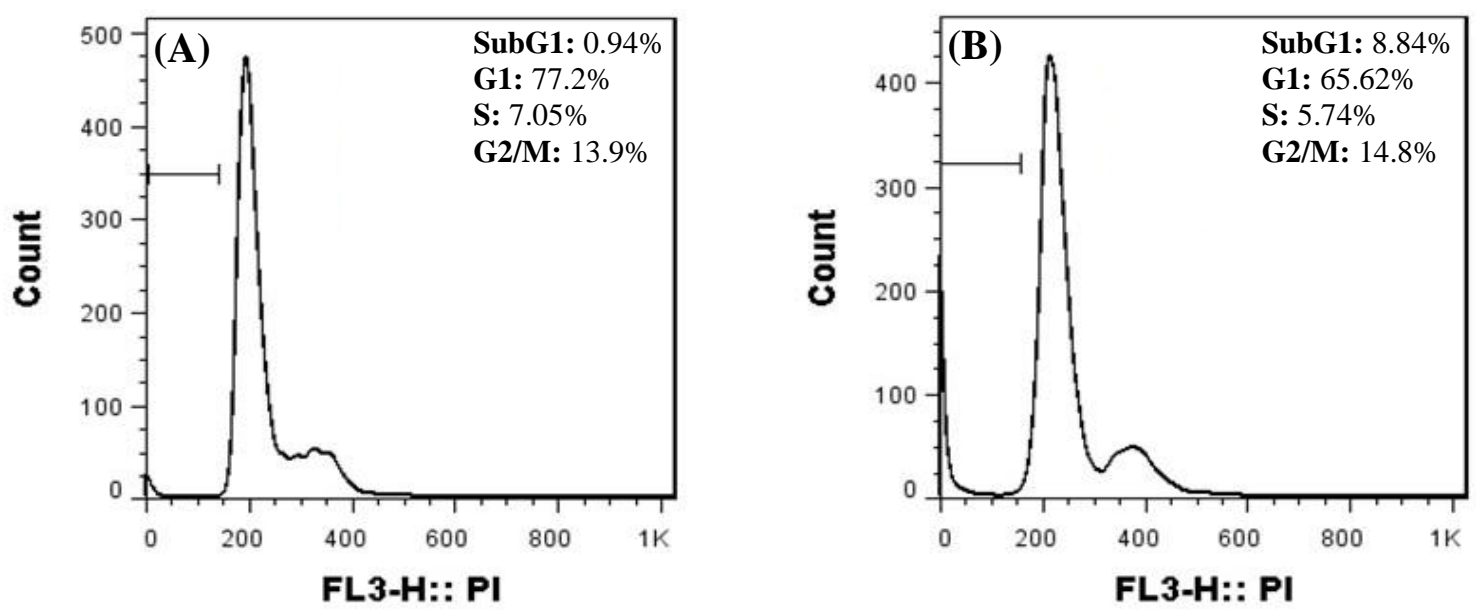

Fig. 4. ZR-75-1 cells were transfected with si-NC (A) and si-lncUSMycN (B). PI staining was done $72 \mathrm{~h}$ after transfection. The range gate illustrated on FACS plots indicates subG1. si-NC, siRNA negative control; si-lncUSMycN, siRNA lncUSMycN; PI, propidium iodide

parental cells or si-NC-treated cells (Fig. 5A). To further investigate the role of lncUSMycN in invasion and metastasis of breast cancer, the expression of Ecadherin, as a EMT marker, and MMP-9 was evaluated. Consistent with the wound healing assay results, depletion of lncUSMycN significantly upregulated E-cadherin in ZR-75-1 cells $(p=0.025)$ but had no significant effect on MMP-9 expression $(p>$ 0.05, Fig. 5B).

\section{DISCUSSION}

Given that breast cancer is the most common cancer among women worldwide ${ }^{[8]}$ and the crucial role of lncRNAs in cancer initiation and progression ${ }^{[9]}$, the present study was undertaken to examine the expression levels of lncRNA lncUSMycN as well as its cellular role in breast cancer. In concordance with Liu et al.' $\mathrm{s}^{[7]}$ findings, our results revealed the elevated expression levels of $\operatorname{lncUSMycN}$ in breast cancer tissues compared to the adjacent non-tumor specimens. The potential value of this lncRNA for early diagnosis of breast cancer was also demonstrated. In addition, cellular function of lncUSMycN was investigated in a cell model to realize its possible role in breast cancer. Attenuation of lncUSMycN was found to result in apoptotic morphological changes and overexpression of EMT marker (E-cadherin) in breast cancer cells.

Inducing apoptosis is an important approach to controlling tumor development. $\mathrm{Bcl}-2$ protein family members such as anti-apoptotic Bcl-2 and pro-
(A) Control

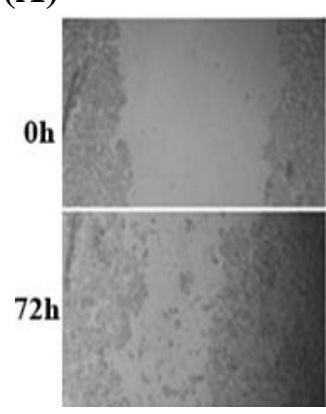

si-NC

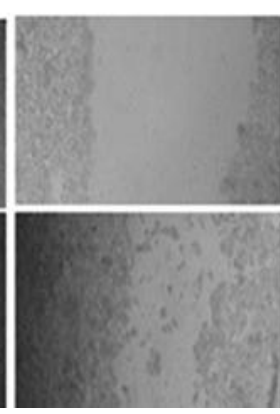

si-IncUSMycN

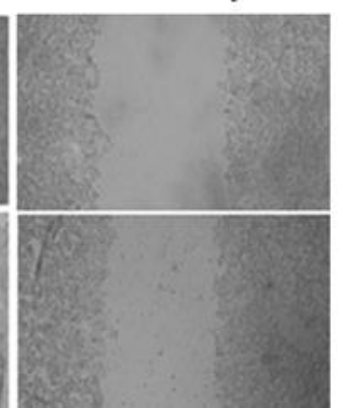

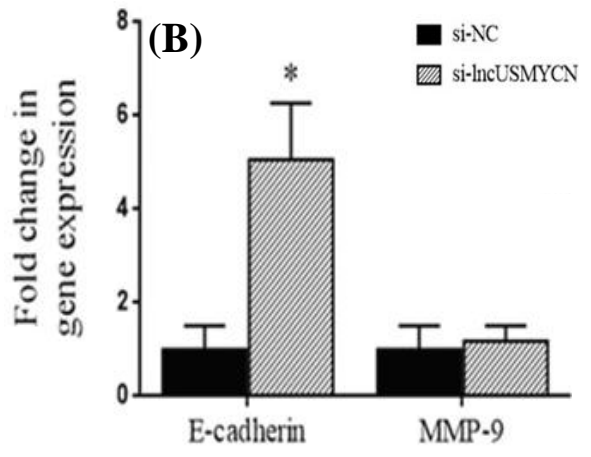

Fig. 5. Effects of lncUSMycN knockdown on epithelial-mesenchymal transition . (A) Scratch wound-healing assay was performed in si-NC and si-lncUSMycN transfected breast cancer cell line ZR-75-1 (magnification 100×); (B) analysis of E-cadhein and MMP-9 expression in ZR-75-1 cells by qRT-PCR $72 \mathrm{~h}$ after transfection $\left({ }^{*} p<0.05\right)$. si-NC, siRNA negative control; si-lncUSMycN, siRNA lncUSMycN 
apoptotic Bax are the key elements in apoptosis ${ }^{[10,11]}$, which make them promising targets in cancer therapy ${ }^{[12,13]}$.

In this study, we showed that IncUSMycN knockdown probably induced apoptosis through the suppression of $\mathrm{Bcl}-2$ and overexpression of $\mathrm{Bax}$ in breast cancer cells. Furthermore, we found that lncUSMycN depletion resulted in significantly lower expression of Bcl-2 and higher expression of $\mathrm{E}$ cadherin in breast cancer cells. In addition, lncUSMycN knockdown significantly suppressed cellular migration. However, lncUSMycN silencing had no significant effect on MMP-9 expression. Our results are consistent with previous studies in which the up-regulation of Bcl-2 led to the loss of E-cadherin and decreased cadherin-mediated cell-cell adhesion as well as invasion ${ }^{[14-16]}$. Hence, our findings further emphasize the critical role of E-cadherin in EMT, which is an important step in metastasis ${ }^{[17,18]}$. Another possible explanation by which IncUSMycN could affect E-cadherin levels might be related to the role of miR-9 in EMT ${ }^{[19]}$. Ma et al. ${ }^{[19]}$ have demonstrated that the activation of pro-metastasis miR-9 by C-Myc and $\mathrm{N}-\mathrm{Myc}$ oncoproteins results in the inhibition of $\mathrm{E}$ cadherin. Given the up-regulation of N-Myc ${ }^{[20,21]}$ and miR-9 ${ }^{[22,23]}$ in breast cancer and increased expression of N-Myc through lncUSMycN ${ }^{[7]}$, we speculate that the same pathways could be involved in reduced cell invasion after lncUSMycN knockdown. However, further functional studies are required to precisely determine the role of $\operatorname{lncUSMycN}$ and its related pathways in cell invasion and apoptosis.

In conclusion, our findings suggest that lncUSMycN is a potential molecular marker for breast cancer and provides further evidence for critical role of this IncRNA in cancer. It also provides preliminary data on the importance of this lncRNA as a possible target therapy against breast malignancy.

\section{ACKNOWLEDGEMENTS}

This study has been conducted at University of Tabriz, Tabriz, Iran and supported by Iranian National Science Foundation (INSF; grant No.93045001). We also thank to staff in Noor-Nejat and Emam Reze Hospitals for cooperation in providing breast cancer specimens.

CONFLICT OF INTEREST. None declared.

\section{REFERENCES}

1. Redig AJ, McAllister SS. Breast cancer as a systemic disease: a view of metastasis. Journal of internal medicine 2013; 274(2): 113-126.

2. American Cancer Society. Breast Cancer Facts \& Figures 2017-2018. Retrieved from: https://www. ncer.org/content/dam/cancer-org/research/cancer-factsand-statistics/breast-cancer-facts-and-figures/breastcancer-facts-and-figures-2017-2018.pdf.

3. Esteller M. Non-coding RNAs in human disease. Nature reviews genetics 2011; 12(12): 861-874.

4. Gibb EA, Brown CJ, Lam WL. The functional role of long non-coding RNA in human carcinomas. Molecular cancer 2011; 10: 38.

5. Batista PJ, Chang HY. Long noncoding RNAs: cellular address codes in development and disease. Cell 2013; 152(6): 1298-1307.

6. Sun XH, Yang LB, Geng XL, Wang R, Zhang ZC. Increased expression of lncRNA HULC indicates a poor prognosis and promotes cell metastasis in osteosarcoma. International journal of clinical and experimental pathology 2015; 8(3): 2994-3000.

7. Liu PY, Erriquez D, Marshall GM, Tee AE, Polly P, Wong M, Liu B, Bell JL, Zhang XD, Milazzo G, Cheung BB, Fox A, Swarbrick A, Hüttelmaier S, Kavallaris M, Perini G, Mattick JS, Dinger ME, Liu T. Effects of a novel long noncoding RNA, IncUSMycN, on N-Myc expression and neuroblastoma progression. Journal of the National Cancer Institute 2014; 106(7): pii: dju113.

8. Jemal A, Bray F, Center MM, Ferlay J, Ward E, Forman D. Global cancer statistics. CA: a cancer journal for clinicians 2011; 61(2): 69-90.

9. Yang G, Lu X, Yuan L. LncRNA: a link between RNA and cancer. Biochemica et biophysica acta 2014; 1839(11): 1097-1109.

10. Gross A, McDonnell JM, Korsmeyer SJ. BCL-2 family members and the mitochondria in apoptosis. Genes and development 1999; 13(15): 1899-1911.

11. Plati J, Bucur O, Khosravi-Far R. Dysregulation of apoptotic signaling in cancer: molecular mechanisms and therapeutic opportunities. Journal of cellular biochemistry 2008; 104(4): 1124-1149.

12. Vervloessem T, Kerkhofs M, La Rovere RM, Sneyers F, Parys JB, Bultynck G. Bcl-2 inhibitors as anti-cancer therapeutics: The impact of and on calcium signaling. Cell calcium 2018; 70: 102-106.

13. Soderquist RS, Eastman A. BCL2 inhibitors as anticancer drugs: a plethora of misleading $\mathrm{BH} 3$ mimetics. Molecular cancer therapeutics 2016; 15(9): 2011-2017.

14. Li L, Backer J, Wong AS, Schwanke EL, Stewart BG, Pasdar M. Bcl-2 expression decreases cadherinmediated cell-cell adhesion. Journal of cell science 2003; 116(18): 3687-3700.

15. Karch I, Schipper E, Christgen H, Kreipe H, Lehmann $\mathrm{U}$, Christgen M. Is upregulation of BCL2 a determinant of tumor development driven by inactivation of CDH1/E-cadherin? PLoS one 2013; 8(8): e73062.

16. Sasaki CY, Lin HC, Passaniti A. Expression of Ecadherin reduces Bcl-2 expression and increases sensitivity to etoposide-induced apoptosis. Cancer cell 
biology 2000; 86(5): 660-666.

17. Thiery JP. Epithelial-mesenchymal transitions in development and pathologies. Current opinion in cell biology 2003; 15(6): 740-746.

18. Myong NH. Loss of E-cadherin and acquisition of vimentin in epithelial-mesenchymal transition are noble indicators of uterine cervix cancer progression. Korean journal of pathology 2012; 46(4): 341-348.

19. Ma L, Young J, Prabhala H, Pan E, Mestdagh P, Muth D, Teruya-Feldstein J, Reinhardt F, Onder TT, Valastyan S, Westermann F, Speleman F, Vandesompele J, Weinberg RA. miR-9, a MYC/MYCN-activated microRNA, regulates Ecadherin and cancer metastasis. Nature cell biology 2010; 12(3): 247-256.

20. Mizukami Y, Nonomura A, Takizawa T, Noguchi M, Michigishi T, Nakamura S, Ishizaki T. N-myc protein expression in human breast carcinoma: prognostic implications. Anticancer research 1995; 15(6B): 28992905.

21. Metge BJ, Mitra A, Chen D, Shevde LA, Samant RSJSr. $\mathrm{N}-\mathrm{Myc}$ and STAT interactor regulates autophagy and chemosensitivity in breast cancer cells. Scientific reports 2015; 5: 11995.

22. Sun Y, Wu J, Wu SH, Thakur A, Bollig A, Huang Y, Liao DJ. Expression profile of microRNAs in c-Myc induced mouse mammary tumors. Breast cancer research and treatment 2009; 118(1): 185-196.

23. Iorio MV, Ferracin M, Liu CG, Veronese A, Spizzo R, Sabbioni S, Magri E, Pedriali M, Fabbri M, Campiglio M, Ménard S, Palazzo JP, Rosenberg A, Musiani P, Volinia S, Nenci I, Calin GA, Querzoli P, Negrini M, Croce CM. MicroRNA gene expression deregulation in human breast cancer. Cancer research 2005; 65(16): 7065-7070 